\title{
Correlates of adults' participation in sport and frequency of sport
}

\section{Corrélats de la participation des adultes en sport et de la fréquence avec laquelle ils le pratiquent}

\author{
A. Oliveira-Brochado ${ }^{a, *}$, P. Quelhas Brito ${ }^{b}$, \\ F. Oliveira-Brochado ${ }^{c}$
}

\author{
a Instituto Universitário de Lisboa, ISCTE Business School, Business Research Unit (BRU-IUL), avenue \\ Forças-Armadas, 1649-026 Lisboa, Portugal \\ b Faculdade de Economia, Universidade do Porto, Rua Dr. Roberto Frias, 4200-464 Porto, Portugal \\ c Instituto Universitário de Lisboa, ISCTE Business School, avenue Forças-Armadas, 1649-026 Lisboa, \\ Portugal
}

Received 2 December 2016; accepted 21 March 2017

Available online 11 July 2017

\section{KEYWORDS}

Hurdle model; Perceived benefits; Frequency of sport; Participation in sport; Correlates

\section{MOTS CLÉS}

Modèle «Hurdle»;
Summary The aim of this research is to analyze the correlates of adults' participation in sport and frequency of sport. A hurdle model approach comprising a binary choice regression to model participation in sport and a count model to address frequency of sport was applied to analyze the data obtained from 516 personal interviews in a Portuguese city. Participation in sport and frequent sport are associated with men, younger people, not married and without children under 2 years, nonsmokers and regular drinkers and with good perceived health. However, participation in sport and frequency of sport participation are associated with different levels of perception of the benefits of sport activity. Whereas awareness of the health and enjoyment benefits fosters participation, fitness, socializing and appearance might increase the frequency of sport. Sport communication strategies might play a prominent role in persuading potential participants of the benefits of sport activity and frequency.

(c) 2017 Elsevier Masson SAS. All rights reserved.

Résumé Le but de cette recherche est d'analyser les corrélats de la participation des adultes en sport et de la fréquence avec laquelle ils pratiquent le sport. Un modèle «Hurdle», comprenant un modèle de régression de choix binaire pour modéliser la participation en sport et un modèle de comptage numérique pour traiter la fréquence du sport, a été appliqué pour analyser

\footnotetext{
* Corresponding author.

E-mail address: ana.brochado@iscte.pt (A. Oliveira-Brochado).
} 
Bénéfices perçus ;

Fréquence de

l'activité sportive ;

Participation en

sport ;

Corrélats les données obtenues par 516 entretiens personnels dans une ville portugaise. La participation en sport ainsi que la fréquence sont associés aux hommes, jeunes, non mariés et sans enfants en dessous de deux ans, qui ne fument pas ni ne boivent régulièrement, et perçus en bonne santé. Cependant, la participation en sport et la fréquence de participation en sport sont associées à différents niveaux de perception des bénéfices de l'activité sportive. Tandis que le savoir relatif aux bénéfices sur la santé et sur le plaisir encourage la participation, la forme physique, la socialisation et l'apparence pourraient augmenter la fréquence de l'activité physique. Les stratégies de communication du sport pourraient jouer un rôle de premier plan pour persuader les participants potentiels des bénéfices de l'activité sportive et de sa fréquence. (c) 2017 Elsevier Masson SAS. Tous droits réservés.

\section{Introduction}

Regular participation in sport among adults has become an important part of a healthy lifestyle benefiting both the mind and the body [1]. On the other hand, physical inactivity has negative implications not only for the individuals, but also for society as a whole, namely in terms of the related financial costs and the implications for government in health care policy, and it has become a major public health concern [1]. At the European level, with the ratification of the Lisbon Treaty in late 2009, Member States recognized the importance of setting a process in motion whereby physical activity and sport are actively promoted not only with a view to increasing health, physical and mental well-being across the European Union (EU), but also to improve the role that sport can play in boosting the social structure. Citizens' right to a culture of physical fitness and sport is also established in national Constitutions. ${ }^{1}$ However, despite these guidelines and the well-recognized benefits of regular physical activity for both participants and communities, there is evidence that large numbers of people in Europe still report being inactive. According to a recent Euro Barometer study [2] on the 27 Member States' sport participation statistics, 61\% of EU citizens report that they seldom or never do sports, 33\% practice sport with some regularity (at least once a week) and $8 \%$ do sports regularly (five times a week or more). Moreover, sport participation in Europe seems to have stagnated [3].

Collectively, these findings emphasize the need to improve sport participation rates for health, economic and social reasons. However, since quality sport participation data is an important prerequisite for designing interventions that effectively meet community needs [4], research is required to identify the correlates of sport participation. Both sport managers and policy makers are motivated to learn more about the variables associated with sport participation and the possible barriers and incentives involved in sport demand. Consequently, there has been growing interest in sport participation research in Europe in recent decades $[5,6]$. Different lines of research have been developed to address this issue and a wide range of demographic,

\footnotetext{
${ }^{1}$ For Example, Article 79 of the Portuguese Constitution establishes the fundamental right of citizens to a culture of physical fitness and sport.
}

psychological, behavioral, social and environmental factors are associated with adult participation in sport.

A large body of the literature has investigated the participation decision (yes/no) and strives to identify the correlates of people's decision to participate in sport. Recent studies have also studied the correlates of the frequency of participation among practitioners [7-10]. These studies have shown that the factors driving the decision to participate or not in sports are different from those determining the frequency of sports. Accordingly, this study is based on the hypothesis that the correlates of sport participation and sport frequency vary.

A recent study by Downward et al. [9] maintained that a policy simply promoting the health benefits of sport participation might not be sufficient and it highlighted that social interaction, personal development and living life to the full are associated with sport participation. The study by Lera-López and Rapún-Gárate [3] revealed that motives such as recreation, keeping slim, fitness, competition and professional development correlate with sport frequency. Collectively, these results suggest the important role of motivation variables in this type of research.

The purpose of this paper is to analyze the correlates of citizens' sport participation and frequency by considering the role of a wide range of sociodemographic and behavioral variables as well as motivational variables. The particular contribution of the paper is to examine the association between perceived benefits of both sport participation and frequency.

The remainder of the paper is structured as follows. The next section provides an overview of the empirical studies of sport activity behavior among adults. This is followed by a description of the methodology adopted in this study, including the research context, the model and data sources employed in the estimations. Some descriptive statistics and the results of the model estimations are then presented and interpreted. We finish with a summary of the main findings and an indication of implications and opportunities for further research.

\section{Literature review}

A number of sport participation studies targeted European countries, such as such as Belgium [11], England [12,13], Spain $[3,10,14]$, Scotland [8] and Germany $[15,16]$. Hovemann and Wicker [17] analyzed sport participation in 25 Member States. 
In the literature review of the correlates of sport activity, some differences emerge. First, the empirical analyses use different measures of sport participation. A large number of studies analyze whether or not individuals perform sport activities (e.g. $[10,12,17,18])$. A second set of studies also analyzes the frequency of participation (e.g., $[7,9,10,14]$ ). Moreover, the duration of the activity [8], the ratio of sports to leisure activities [13] and the sport expenditures [14,19] were also analyzed.

As a consequence, various regression techniques have been applied in the empirical analysis of sports participation. The first set of studies uses probit models [12], binary logistic regression [11], or logistic regression analysis $[15,17,18]$ to analyze the correlates of sport participation (yes/no).

The second set of studies also examine the frequency of participation, i.e., the number of times an individual practices sports during a certain period; these have employed Heckman selection models [7], zero inflated ordered probit $[3,9,10]$ and ordered probit models [14]. Tobit regressions $[13,20]$ and "copula" estimators [8] have also been applied.

Despite the different approaches and models applied in the empirical evidence general assessments can be made regarding the role played by different variables, such as demographic (gender, age), household related (marital status, number of children), socioeconomic (income, occupation, education), health related (smoking and drinking behaviors, perception of health) and perceived sport benefits. Hereafter, we use sport participation to denote whether or not the individual practice sports and sport frequency to refer to the frequency of that participation.

In general, men are more likely to participate in sports than women $[8,13-15,18,21,22]$. This can be explained not only by the physical differences between women and men, but also by social and psychosocial constraints that originate from differences in family responsibilities [23]. Hovemann and Wicker [17] concluded that although men exhibit higher participation rates than woman, women are more active than men in 2 of the 25 member states, namely the Netherlands and Denmark. Breuer et al. [15] concluded that man typically do cycling, running, football and tennis, whereas females do swimming, fitness, gymnastics, walking and dancing.

As regards sport frequency, Lera-López and Rapún-Gárate [14] reported that although men have a higher level of participation, this is not the case for sport frequency among practitioners. In contrast, Downward et al. [9] concluded that men are more likely to both participate and exhibit higher frequency levels than females. Moreover, Lera-López and Rapún-Gárate [3] found that women show higher sport participation than men.

Sport participation is negatively correlated with age in a linear or a nonlinear way $[7,8,12,14,18]$. Wicker et al. [16] conclude that age does not play a role in explaining sport participation and maintain the explanation for this might lie in the broad definition of sport used in the analysis, which included activities such as walking and jogging.

However, recent studies have noted that declining sport participation levels with age should be interpreted with caution, at least in explaining the frequency of participation. The study by Downward and Riordan [7] revealed that age is not correlated with frequency. Lera-López and Rapún-
Gárate [14] conclude that age is positively related with frequency as the upper age group (56-65 years) practice sport more often than the lower age group (16-25 years). Lera-López and Rapún-Gárate [3] obtain the same result. Downward et al. [9] suggest that there is a nonlinear effect of age on the decision to participate and in the frequency of participation and that this result could be explained by the increasing awareness of the health benefits of sports participation among the elderly or their sports literacy as compared to younger generations. Moreover, the elderly have more time available for leisure and sporting activities Lera-López and Rapún-Gárate [3]. The older population demonstrate increasing concern about and awareness of their well-being [14]. Muñiz et al. [10] conclude that the young and elderly people have a higher probability of sport participation and sport frequency and maintained that this result may be linked to the life cycle.

Household characteristics such as being married $[8,10,12]$ and having children $[8,10]$ are found to have a negative impact on sport participation. These results suggest that housekeeping and childcare act as barriers to sport participation, limiting the time available for sports in general. The individual allocation of time is known to be constrained by the distribution of activities among household members [3]. However, children may foster participation in child-oriented sport activities such as swimming $[7,24]$.

In terms of sport frequency, Muñiz et al. [10] concluded that being married and having children reduces the frequency of sport participation and that the influence is greater for women.

The literature provides evidence that a lower income may act as an obstacle to sport participation [5,8,13,21,25,26]. For example, the income variable affects negatively purchase intention in the case of US tennis participants [27]. However, Downward and Riordan [7] conclude that income is not relevant in the decision to participate in sports.

Nevertheless, income has no influence on the frequency of the sports participation of regular practitioners, LeraLópez and Rapún-Gárate [3] and is not even negatively correlated with sport frequency Downward and Riordan [7]. This might be explained by the fact that the higher income, the greater the opportunity cost of time spent on any leisure activity.

Kokolakakis et al. [18] maintained that having a high occupational status has a positive effect on sport participation, while unemployment and retirement have a negative effect. However, it should be noted that unemployment simultaneously implies having more free time but less income to spend. According to Lera-López and Rapún-Gárate [14], workers in general report a lower level of sport activity and a higher level of expenditure than the economically inactive population.

Education is positively related to sport participation $[9,12,13,17,18,22,25,26]$. This could be due to a greater awareness of the benefits and importance of sport or to the habits developed as students.

The study conducted by Lera-López and Rapún-Gárate [3] revealed that educational levels are not related with frequency.

Scheerder et al. [11] concluded that people from the higher social classes participate in sport more than 
people belonging to the lower classes. However, their study revealed also that the effect of social class has declined slightly over a decade.

Downward et al. [9] found that social class is positively associated with frequency, but a higher social class does not necessarily increase the probability of participating.

According to previous studies $[1,7,12]$, sport participants tend to drink alcohol and do not smoke. This suggests a distinction between factors of a healthy lifestyle. Less activity among smokers may reflect smokers' lower discount rate for health [8]. As regards drinking, individuals who consume alcohol are generally sociable and participation in sport serves as a social inclusion or networking device.

Downward and Rasciute [20] conclude a higher ratio of sports to leisure activities is likely to occur to respondents identifying better perceived health. The decision to participate increases for those who have a self-perception of being healthier $[1,7,12]$. Being obese lowers the likelihood of being active [8].

Muñiz et al. [10] found the paradoxical result that people with a chronic illness participate in sports more often and highlight that sports might have a therapeutic effect. Downward and Riordan [7] concluded that the frequency of participation also rises for those who have a perception of being healthier.

The empirical evidence shows that perceived benefits and motivations act as strong correlates of sport participation [1,3]. Davey et al. [28] classify intrinsic and extrinsic motivations of sport participation into five groups: health and fitness, enjoyment, appearance, social and competition/challenge. Anokye et al. [1] add that participants who feel sports can help them relax and forget about their worries or/and help them look attractive are more active compared with those with less awareness.

Downward et al. [9] studied the effect of motivations to participate in sport and concluded that participants seem to value the social interaction, living life to the full and personal development. Sport participation seems to be motivated not only by keeping fit but also socializing. Lera-López and Rapún-Gárate [3] conclude that some motivational factors such as recreation, keeping slim and fit, competition and professional development act as predictors of the frequency of sport participation. Berger et al. [29] concluded that the adolescents that regularly participate in sports also report self-perceptions of health, enjoyment of social activities and knowing neighbors.

The literature reveals a large number of variables correlated with sport participation and sport frequency. Given the differences found in the literature between the correlates of sport participation and sport frequency, this work employs two dependent variables.

\section{Method}

\subsection{Sport participation measures}

Sport research has been unable to provide a common definition of sport [30]. According to the European Sports Charter, "sport means all forms of physical activity which, through casual or organized participation, aims at expressing or improving physical fitness and mental well-being, forming social relationships or obtaining results in competition at all levels' (Council of Europe, 1992, article 2, p. 1). Lera-López and Rapún-Gárate [14] highlighted a change in the actual concept of sport, namely from that of an organized and competitive practice to a much broader concept involving organized, noncompetitive, recreational sporting activity. In light of this, activities such as walking and jogging were included in the present study. As in Kokolakakis et al. [18], participation in sports is broadly defined by two criteria:

- it must require a regular and planned physical activity lasting at least 20 minutes once a week;

- it must be for recreational purposes or involve a competitive element. We attempted to exclude episodes of a very short duration by introducing a minimum time for the activity.

\subsection{Survey design}

This work employs quantitative study and a survey was drafted accordingly. The data about sport participation was collected by asking participants whether they do sports in their free time (yes/no). If the response was affirmative, they were then asked to select from a list the sports activities (e.g., walking, jogging and running, football, volleyball, swimming, gymnastics, fitness, dancing) in which they are regularly involved during their leisure time. Participants in sport activities were also asked to provide information regarding the frequency of participation (number of times a week sport was undertaken).

The independent variables were selected on the basis of the literature reviewed. As primary data was gathered, a broad set of variables were included in the analysis in the belief that they would enable a segmentation of the population and could be used to design plans to enhance sport participation.

Accordingly, the interview script covered demographic data, such as gender (male versus female) and age. The respondents were asked to indicate whether they have children and their marital status. Moreover, a social class composite index was obtained based on household income, education and professional activity and respondents were classified into AB, C1, C2 and D class according to the Nielsen Index approach. The survey also included questions related to smoking and drinking habits. General health status was assessed by a Likert scale, ranging from 1 (poor health) to 7 (excellent health). The body mass index (BMI) was used as input in a health outcome context, reflecting food intake preferences. Therefore, respondents were asked to provide their weight and height. In order to access psychological well-being, participants reported whether they had felt anxious or depressed during the last month or if they had used a psychotropic (to stay calm or to sleep).

The question for perceived benefits was "tell me how much you would say sports and exercise could help people in the following things:" and each item was measured using a score for each health and non-health benefit ranging from 1 (not at all) to 7 (a great deal). The score reflects how much a person thought sports could help individuals to achieve each of the 8 benefits. 
The first draft of the survey was pretested by means of personal interviews conducted by the researcher in a gymnasium with two personal trainers and a sport manager and six active adults to ensure the validity of the research instrument. They were asked to answer the questionnaire in the presence of the researcher who observed whether they fully understood the questions and the wording. Moreover, in order to ensure content validity of the 8 perceived benefits (adapted from previous studies), participants were also asked in the pretest whether there were any other benefits not listed in the survey that they thought sport participation could help people achieve. The benefits mentioned were found to be comparable to those already listed.

\subsection{Research context and participants}

The resident adult population in the city of Guimarães, a Portuguese city, was the target for this study. Portugal has below average sport activity [31]. Indeed, a worrying statistic from a public health perspective is that $55 \%$ of those surveyed never do sports, $66 \%$ seldom do sports, and only $24 \%$ take part in sports with some regularity. Only a healthy minority of respondents in Portugal - $9 \%$ - could be considered serious sport participants, doing sport 5 times a week or more [2]. Guimarães is the historical capital of Portugal and received the UNESCO classification of World Heritage in 2001. It was awarded the European Capital of Culture 2012 and the European Capital of Sport in 2013. Guimarães is a small European city that encompasses a region with a total land area of $241.05 \mathrm{~km}^{2}$ with about 160,000 inhabitants (Census 2011, INE-Statistics Portugal). Guimarães has a total of 317 sport facilities, comprising 117 multi-sport facilities, 70 football pitches, 30 sport pavilions, 21 gymnasiums, 19 swimming pool facilities and 13 public leisure parks (Guimarães City Hall, 2012). The participation rate in sports is above the national average (CMG, 2012).

In order to guarantee a representative sample, data were collected based on non-probabilistic quota sample technique with two non-related variables, age and gender. A total of 516 face-to-face questionnaire surveys were administered by trained interviewers who performed mallintercept interviews and the fieldwork was conducted by an outsourced company, yielding a confidence level of $95 \%$ and a sampling error of \pm 0.04 .

\subsection{Data treatment}

First, descriptive data analyses were performed. Then, a hurdle model was estimated. As the estimated alpha parameter was greater than zero and significant $(\alpha=.231$, $P<.001$ ), a logit-negative binomial model was adopted do cope with over dispersion [32].

The hurdle model could be viewed in terms of two decisions. In the sport participation context, one decision is whether to be a sport participant. This is equivalent to a decision as to whether the count will be zero (non participant) or positive (participant). The second decision is the number of occurrences, in the case of a positive count. The formal model is:

$z=$ if the response is zero, 1 if the response is positive

$y=$ the number of occurrences if the count is positive

The hurdle model can be assembled from any desired binary choice and count model, consisting of two parts:

$P\left[z=0\right.$ or $\left.1 \mid x_{i}\right]=$ a logit model

$P\left[y=j|y>0| x_{1} i\right]$

$=$ a count data model with truncation at zero

The modelling exercise involves fitting a hurdle model for two dependent variables (whether or not the respondent does sports regularly at least once a week and the number of days a week when sport was undertaken for at least 20 minutes) of the reported participation rates on the reported demographic, economic and psychographic factors. The advantage of using a hurdle model is to simultaneously allow the main correlates for being active to be identified and to explain why some individuals do more sports than others. Robust standard errors are calculated in order to deal with heteroscedasticity issues.

\section{Results}

\subsection{Demographic and socioeconomic profile}

The sample was comprised of $65.8 \%$ female respondents and $45.2 \%$ male respondents. The average age was 33.29 years $(S D=13.27)$. About $10 \%$ were classified in the $A B$ social class, $32.6 \%$ in $\mathrm{C} 1,48.5 \%$ in $\mathrm{C} 2$ and $8.8 \%$ in $\mathrm{D}$. The average size of the household was $3.44(S D=1.45)$ and $22 \%$ of the respondents had children under 18 years living with them. The majority of the respondents (63.8\%) had a normal (healthy) weight. About $4.7 \%$ were underweight, $25.4 \%$ were overweight and $4.8 \%$ were class I obese (moderately obese).

\subsection{Sport participation and frequency}

About $46 \%$ of the respondents had not participated in any sports during the last month. The most common sports are as follows: football $(24 \%)$, fitness/gymnastics (12\%), swimming (11\%), walking $(9 \%)$, cycling $(5 \%)$, running and jogging $(4 \%)$ and dancing (3\%). On average, people who are physically active exercise 2.23 days a week $(S D=1.88)$.

\subsection{Perceived benefits}

The median score for 7 of the 8 items of perceived benefits was 4 or more: "improve or maintain health and well-being" $(M=5.79)$, "improve physical performance", $(M=5.52)$, "improve appearance" $(M=5.42)$ and "lose or maintain weight"' $(M=5.41)$ were the most perceived benefits arising from sports. The benefits "get together and meet other people"' $(M=5.36)$, "have fun" $(M=4.39)$, "relax, 
Table 1 Sample characteristics.

\begin{tabular}{|c|c|c|c|c|c|}
\hline & Category & $\mathrm{N}$ & $\%$ & Mean & S.D. \\
\hline \multirow[t]{2}{*}{ Gender } & Female & 283 & 55 & & \\
\hline & Male & 233 & 45 & & \\
\hline \multirow[t]{5}{*}{ Age Group } & $18-24$ & 101 & 20 & & \\
\hline & $25-34$ & 211 & 41 & & \\
\hline & $35-44$ & 125 & 24 & & \\
\hline & $45-55$ & 58 & 11 & & \\
\hline & $56-65$ & 21 & 4 & & \\
\hline \multirow[t]{3}{*}{ Marital status } & Single & 110 & 21 & & \\
\hline & Married/together & 327 & 63 & & \\
\hline & Divorced/widowed & 79 & 15 & & \\
\hline \multirow[t]{3}{*}{ Children } & Children under 2 & 64 & 12 & & \\
\hline & Children 2-18 & 53 & 10 & & \\
\hline & No children/children +18 & 399 & 77 & & \\
\hline \multirow[t]{4}{*}{ Social class } & $A B$ & 51 & 10 & & \\
\hline & $\mathrm{C} 1$ & 166 & 33 & & \\
\hline & $\mathrm{C} 2$ & 247 & 49 & & \\
\hline & $\mathrm{D}$ & 45 & 9 & & \\
\hline \multirow[t]{3}{*}{ Smoking status } & Smoker & 141 & 27 & & \\
\hline & Ex-smoker & 25 & 5 & & \\
\hline & No smoker & 350 & 68 & & \\
\hline \multirow[t]{3}{*}{ Drinker status } & Regular over limit drinker & 77 & 15 & & \\
\hline & Regular under limit drinker & 107 & 21 & & \\
\hline & No Drinker/occasional drinker & 332 & 64 & & \\
\hline \multirow[t]{2}{*}{ Health } & General health status & & & 4.89 & 1.7 \\
\hline & BMI Overweight/obese & 163 & 31.5 & & \\
\hline Psychological wellbeing ${ }^{a}$ & Depressed/anxious/psychotropic & 134 & 26 & & \\
\hline \multirow[t]{8}{*}{ Perceived Benefits } & To improve or maintain health and well-being & & & 5.79 & 0.76 \\
\hline & To improve physical performance & & & 5.52 & 0.72 \\
\hline & Loose or maintain weight & & & 5.61 & 1.01 \\
\hline & Improve appearance & & & 5.72 & 0.87 \\
\hline & To get together and meet other people & & & 5.36 & 0.98 \\
\hline & To relax, forget about our cares & & & 4.21 & 1.15 \\
\hline & To have fun & & & 4.39 & 1.50 \\
\hline & To feel a sense of achievement & & & 3.20 & 1.10 \\
\hline
\end{tabular}

a Total respondents who answer only one choice.

forget about our cares' $(M=4.21)$ were also perceived by the respondents. Table 1 presents the sample characteristics.

\subsection{Hurdle model estimates}

A summary of the results about the individual correlates on sport participation appears in Table 2. Two sets of the estimation results are presented. Table 1 contains the parameters of the regression considering participation for at least 20 minutes per week (yes/no) as the dependent variable. Table 2 exhibits the results for the frequency (number of days per week) model.

Firstly, there is a significant gender effect. Men report higher levels of sport participation and frequency than females. Age is statistically related to sport participation. As intuition would suggest, participation is more likely among younger individuals. Nevertheless, age is almost irrelevant in explaining the frequency of participation. Today's elderly have more time available for leisure and sporting activities.
When older people start to participate, the frequency of participation may reach a similar level to that of young people. Another explanation for this may lie in the broad definition of sport adopted in this study, which includes activities such as walking [14].

Married people are less active compared with single/divorced people, and having children under 2 years has a significant negative effect on sport participation and frequency. These results suggest that housekeeping and childcare act as barriers to sport participation.

The results revealed that individuals belonging to the lower $(A B)$ and the upper class (D) are less likely to participate in sports. However, these differentials may be explained by different factors. The lower social class population might be less aware of the health benefits of a physically active lifestyle and sport expenses (sports club or gym membership fees and investment in sport equipment) act as a barrier to sport participation. On the other hand, the upper social classes have access to a wider range of entertainment options and more opportunity to substitute sports with other leisure activities. 
Table 2 Model results.

\begin{tabular}{|c|c|c|c|c|c|c|}
\hline \multirow[t]{2}{*}{ Variables } & \multicolumn{3}{|c|}{$\begin{array}{l}\text { Sport participation } \\
\text { (Logit model) }\end{array}$} & \multicolumn{3}{|c|}{$\begin{array}{l}\text { Frequency of sport participation } \\
\text { (Negative binonial) }\end{array}$} \\
\hline & B & & SE & B & & SE \\
\hline Male & 0.38 & \multirow[b]{2}{*}{$* * *$} & 0.04 & 0.28 & $* * *$ & 0.08 \\
\hline Age group 18-24 & 0.45 & & 0.15 & 0.12 & \multirow{4}{*}{$*$} & 0.07 \\
\hline Age group 25-34 & 0.23 & \multirow{2}{*}{ "** } & 0.11 & 0.04 & & 0.04 \\
\hline Age group $35-44$ & 0.14 & & 0.07 & 0.03 & & 0.03 \\
\hline Age group 45-55 & 0.08 & \multirow[b]{2}{*}{$* *$} & 0.27 & 0.03 & & 0.03 \\
\hline Married/cohabitation & -0.23 & & -0.10 & -0.15 & \multirow{3}{*}{$\begin{array}{l}\text { * } \\
\text { *** } \\
\text { ** }\end{array}$} & -0.08 \\
\hline Children under 2 & -0.182 & $* * *$ & -0.06 & -0.12 & & -0.03 \\
\hline Children 2-18 & -0.11 & \multirow{3}{*}{${ }_{* * *}^{* *}$} & -0.12 & -0.01 & & -0.01 \\
\hline Social class C1 & 0.167 & & 0.08 & 0.1 & \multirow{5}{*}{ ** } & 0.07 \\
\hline Social class C2 & 0.378 & & 0.10 & 0.09 & & 0.06 \\
\hline Social class D & 0.10 & \multirow[b]{2}{*}{ ** } & 0.17 & 0.02 & & 0.01 \\
\hline Ex-smoker & 0.105 & & 0.05 & 0.06 & & 0.04 \\
\hline Smoker & -0.06 & \multirow[b]{2}{*}{$* *$} & -0.07 & -0.25 & & -0.10 \\
\hline Regular over limit drinker & 0.17 & & 0.07 & 0.11 & \multirow{2}{*}{${ }_{* * *}^{* *}$} & 0.05 \\
\hline Regular under limit drinker & 0.18 & ** & 0.09 & 0.1 & & 0.03 \\
\hline General health status & 0.33 & \multirow{2}{*}{$\begin{array}{l}* \star * \\
* *\end{array}$} & 0.10 & 0.25 & $* * *$ & 0.05 \\
\hline BMI overweight/obese & -0.25 & & -0.12 & -0.12 & \multirow{2}{*}{${ }^{* * *}$} & -0.02 \\
\hline Depressed/anxious/pychotropics & -0.06 & \multirow[b]{2}{*}{$* * *$} & -0.05 & -0.44 & & -0.15 \\
\hline Improve or maintain health and well-being & 0.44 & & 0.09 & 0.23 & \multirow[b]{2}{*}{$* * *$} & 0.05 \\
\hline To improve physical performance & 0.09 & \multirow{3}{*}{$\begin{array}{l}* * * \\
* * *\end{array}$} & 0.18 & 0.33 & & 0.13 \\
\hline To improve fitness & 0.42 & & 0.05 & 0.09 & \multirow{4}{*}{$* * *$} & 0.08 \\
\hline Lose or maintain weight & 0.23 & & 0.05 & 0.05 & & 0.04 \\
\hline Improve physical appearance & 0.12 & \multirow[b]{2}{*}{ ** } & 0.10 & 0.51 & & 0.19 \\
\hline To have fun & 0.22 & & 0.11 & 0.03 & & 0.02 \\
\hline
\end{tabular}

Note: significance level of $0.1 \%\left(^{* * *}\right), 1 \%\left(^{* *}\right)$ and $5 \%\left(^{*}\right)$.

However, social class is not associated with the frequency with which regular practitioners do sport.

Among lifestyle variables, nonsmokers are more likely to participate and also to be more active than smokers. Exsmokers are also more likely to participate than smokers. Drinkers are more likely to participate than those who never or occasionally consume alcohol.

As expected, a self-perception of good health is correlated is associated with sport participation. Although it is not possible to ascertain whether good health is a result of the sporting activities in the past, the conclusion can be drawn that it is also correlated with sport participation.

Being obese is also associated with a lower likelihood of being active and less frequency among practitioners. In relation to psychological well-being, depressive and anxious states are less frequent among the more active practitioners. It is worth clarifying that correlation does not necessarily imply a causal relationship, which cannot be identified in the present study.

The empirical evidence shows that the most relevant benefits in sport participation are health, fitness, enjoyment and relaxation. Some important differences emerge when only frequency among practitioners is taken into consideration. Among regular participants, physical appearance, performance and socializing aspects act as a strong predictor of the frequency of sport participation.

This study also confirms the idea that adults perceive they may improve their health by participating in sports. Adults who participate in sport activities are also aware of enjoyment and relaxation benefits. Sport participation and sport frequency are also related socializing.

To sum up, the empirical results suggest that sport participation and frequency may be determined by individual and social characteristics (age, gender and marital status), economic factors (social class), health status (self-perception of physical and mental well-being) and be associated with other lifestyle behaviors (such as smoking and drinking). The findings of this study are in keeping with those published in the literature. The main differences regarding sport participation and sport frequency are associated with different levels of perception of the benefits of sport activity.

\section{Conclusion}

The importance of sport activities has led to an emergent and growing empirical literature focusing on the correlates of sport activity among the adult population. This work further investigates this issue by attempting to identify the influence of different variables on sport participation and sport frequency. The variables included in this study were selected on the basis of the literature reviewed and on the assumption that they might act as useful tools when it comes to devising strategies in the field of sport management. The study was conducted in Portugal, known to be one of the less active countries in the European Union. 
The results revealed that sport activity and sport frequency are associated with being male, younger, not married, without children and with good health. The social class correlates with sport participation but not with sport frequency.

The estimation of a hurdle model demonstrated that sport participation and sport frequency are associated with different levels of perception of the benefits of sport activity. Specifically, awareness of the health, socialization and enjoyment benefits foster participation, whereas fitness, socializing and appearance might increase sport frequency. This result provides further evidence on the role of perceived benefits in sport participation studies, adding to the results by Lera-López and Rapún-Gárate [3] and Downward et al. [9].

Understanding the factors that attract people to sport as well as those that are associated with greater commitment levels might provide insights, which permit target areas for interventions to be identified. The managerial implications of the obtained results can now be discussed. Since the highest participation occurs typically in people with good health, normal weight and nonsmokers, primary health care professionals should continue to encourage sport participation especially among those who really need it.

If the goal is to increase the sport participation, attention should be focused on women, married people and those with children under the age of two. Therefore, any offer targeting these groups should address childcare and housekeeping issues.

Strategies to encourage people to take up may not be effective in encouraging those who already participates to do more sports. For example, targeting those that belong to the lower or upper social classes might raise the frequency of participation among those who are inactive but have no impact on frequency among participants.

Belonging to a middle-lower or lower social class is shown to be a barrier to sport participation in the study sample. Therefore, any policy aiming to boost the numbers of physically active individuals amongst this group should take this factor into account where there are financial constraints on sport participation. Moreover, if it is assumed that the less educated are less aware of the health benefits of sport participation, information initiatives are warranted in this group. Whereas an economic effect could be argued for the lower social class, a substitution effect might justify the lower levels of participation for the upper class.

The results on general health show that sport participation is associated with good health and normal weight. The people who are active are typically nonsmokers. Therefore, the role played by primary health care professionals in recommending sport participation for health motives should also be highlighted.

Given the multiple benefits attributed to sport activities, the results suggest different strategies and actions to boost sport participation and sport frequency. First of all, marketing communication strategies aimed at attracting new sport participants should emphasize the positive benefits of sports in terms of health, recreational value and relaxation. On the other hand, promotion of physical performance and appearance might encourage a higher rate of frequency. Communication campaigns should promote awareness about the non-health benefits of participation in sports.
As a final word, this research presents some limitations, mainly in relation to the data and variables used. The first issue deserving attention is the measurement method of sport participation via self-reported indicators. Although this approach is known to enable the collection of comprehensive information on the respondents' activity type and frequency with low cost implications and burdens on participants, it might also be subject to overestimation, understating sedentary behavior and problems of recall. The survey gathers data for several variables by means of selfperception evaluations. Therefore, endogeneity might be an issue for variables such as the BMI. Indeed, the estimates provided only enable the identification of variables that are associated with sports participation.

Similarly, we did not separate the environment in which participants experienced exercise: natural (outdoors) or artificial (indoors) [33].

This work strives to analyze the drivers of sport participation and sport frequency. Further studies could also address the drivers of meeting the recommended level of sport participation for health benefits, as well as the duration and intensity of the workout. The modes and settings and also the types of sport participation seem to be age dependent. Moreover, future studies could analyze how the adoption of team/collective versus individual sports and organized/competitive versus noncompetitive sport participation influences the evaluation of benefits. Similarly, a deeper analysis should be made about the role of drivers of sport participation in different types of sports and other aspects such as participation in multiple sport activities versus single activities.

In conclusion, it is important to continue to probe the perceived benefits of sport participation, frequency, duration and intensity by different participants. This would provide further insights on how the sport offer and communication could be better designed and implemented to attract more participants and to increase the participation among those who are already active.

\section{Disclosure of interest}

The authors declare that they have no competing interest.

\section{References}

[1] Anokye NK, Pokhrel S, Buxton M, Fox-Rushby J. The demand for sports and exercise: results from an illustrative survey. Eur J Health Econ 2012;13(3):277-87.

[2] European Commission. Special Eurobarometer. Sport Phys Activ 2014;412 [Retrieved from http://ec.europa.eu/health/ nutrition_physical_activity/docs/ebs_412_en.pdf].

[3] Lera-López F, Rapún-Gárate M. Determinants of sports participation and attendance: differences and similarities. Int J Sports Mark Sponsor 2011;12(2):167-90.

[4] Eime RM, sawyer N, Harvey JT, Casey MM, Westerbeek H. Integrating public health and sport management: sport participation trends 2001-2010. Sport Manag Rev 2015;18(2):207-17.

[5] Wicker P, Breuer C, Pawlowski T. Promoting sport for all agespecific target groups: the impact of sport infrastructure. Eur Sport Manag Q 2009;9:103-18. 
[6] Downward P, Lera-López F, Rasciute S, Robinson L, Chelladurai $P$, Bodet G, Downward PM. The economic analysis of sport participation. Handb Sport Manag 2012:331-53 [Routledge].

[7] Downward P, Riordan J. Social interactions and the demand for sport: an economic analysis. Contemp Econ Policy 2007;25:518-37.

[8] Eberth B, Smith MD. Modeling the participation decision and duration of sporting activity in Scotland. Econ Model 2010;27:822-34.

[9] Downward P, Lera-López F, Rasciute S. The zero-inflated ordered probit approach to modelling sports participation. Econ Model 2011;28(6):2409-77.

[10] Muñiz C, Rodiguez P, Suárez MJ. Sports and cultural habits by gender: an application using count data models. Econ Model 2014;36:288-97.

[11] Scheerder J, Vanreusel B, Taks M. Stratification patterns of active sport involvement among adults social change and persistence. Int Rev Sociol Sport 2005;40:139-62.

[12] Farrell L, Shields MA. Investigating the economic and demographic determinants of sporting participation in England. J R Stat Soc 2002;165:335-48.

[13] Humphreys BR, Ruseski JE. Participation in physical activity and government spending on parks and recreation. Contemp Econ Policy 2007;25:538-52.

[14] Lera-López F, Rapún-Gárate M. The demand for sport: sport consumption and participation models. J Sport Manag 2007;21(1):103-22.

[15] Breuer C, Hallmann K, Wicker P. Determinants of sport participation in different sports. Manag Leis 2011;16(4):269-86.

[16] Wicker P, Hallmann K, Breuer C. Micro and macro level determinants of sport participation. Sport Bus Manag 2012;2(1): $51-68$.

[17] Hovemann G, Wicker P. Determinants of sport participation in the European Union. Eur J Sport Sociol 2009;6(1):51-9.

[18] Kokolakakis T, Lera-López F, Panagouleas T. Analysis of the determinants of sports participation in Spain and England. Appl Econ 2012;44(21):2785-98.

[19] Thibaut E, Vos S, Scheerder J. Hurdles for sports consumption? The determining factors of household sports expenditures. Sport Manag Rev 2014;17:444-54.

[20] Downward P, Rasciute S. The relative demands for sports and leisure in England. Eur Managt Q 2010;10(2):189-214.
[21] Wilson TC. The paradox of social class and sports involvement: the roles of cultural and economic capital. Int Rev Sociol Sport 2002;37:5-16.

[22] Downward P. Exploring the economic choice to participate in sport: results from the 2002 General Household Survey. Int Rev Appl Econ 2007;21:633-53.

[23] Chalabaev A, Sarrazin P, Fontayne P, Boiché J, ClémentGuillotin C. The influence of sex stereotypes and gender roles on participation and performance in sport and exercise: review and future directions. Psychol Sport Exerc 2013;14:136-44.

[24] Downward P. On leisure demand: a post Keynesian critique of neoclassical theory. J Post Keynes Econ 2004;26:371-94.

[25] Stempel C. Adult participation sports as cultural capital: a test of Bourdieu's theory of the field of sports. Int Rev Sociol Sport 2005; 40:411-32.

[26] Breuer C, Wicker P. Demographic and economic factors concerning the inclusion in the German Sport System. A micro-analysis of the years 1985 to 2005. Eur J Sport Soc 2008;5:35-43.

[27] Casper J. Sport commitment, participation frequency and purchase intention segmentation based on age, gender, income and skill level with US tennis participants. Eur Sport Manag Q 2007;7(3):269-82.

[28] Davey J, Fitzpatrick M, Garland R, Kilgour M. Adult participation motives: empirical evidence from a workplace exercise programme. Eur Sport Manag Q 2009;9(2):141-62.

[29] Berger IE, O’Reilly N, Séguib MM, Hernandez T. Determinants of sport participation among Canadian adolescents. Sport Manage Rev 2008;11:277-307.

[30] Rowe K, Shilbury D, Ferkins L, Hinckson E. Sport development and physical activity promotion: an integrated model to enhance collpaboration and understanding. Sport Manag Rev 2013;16:364-77.

[31] Tuyckom CV. Six sporting worlds. A cluster analysis of sports participation in the EU-25. Qual Quant 2013;47(1):441-53.

[32] Cameron AC, Trivedi PK. Econometric models based on count data: comparisons and applications of some estimators and some tests. J Appl Econometr 1986;1:29-54.

[33] Salome L, Bottenburg Mvan. Are they all daredevils? Introducing a participation typology for the consumption of lifestyle sports in different settings. Eur Sport Manag Q 2012;12(1):19-42. 